This is the final pre-publication version of a book chapter from:

Anne Coles, Leslie Gray and Janet Momsen (eds) (2015) A Handbook of Gender and Development. London: Routledge.

\title{
Gender, development, children and young people
}

Jo Boyden, Gina Crivello \& Virginia Morrow, Young Lives, Oxford.

\section{Introduction}

Most of the world's children live in developing countries, and children and young people are a major focus of intervention in international development. Yet despite the success of recent feminist critiques in shifting focus within academic and policy circles from 'women' to 'gender' and foregrounding questions of power relations and equality, children and young people are marginal in gender and development debates, and the gender-development nexus continues to be explored mainly through the lens of adult experience. When children do appear, the focus is often on their relationship to women/mothers and to processes of female poverty and the attention given to girls rather than gender per se, emphasis being given to their victimization through diverse 'harmful practices' and to the women they will become (see for example UNICEF's State of the World's Children reports 2007, 2008, and 2009, concentrating, respectively, on 'Maternal and Newborn Health', 'Women and Children - Child Survival' and 'Women and Children - The double dividend of gender equality'). Though gender in childhood and youth receives some consideration within social anthropology, social geography and childhood studies, international development engagement with this literature has been negligible.

We suggest that international development needs to pay greater attention to gender in childhood and youth. We make four key points: 1) that the international development discourse is neglectful of children's gendered experiences; 2) that gender in childhood is influenced by intra-household forces, socio-cultural context, institutional structures and economic pressures; 3) that gendered disparities do not always conform to conventional assumptions; 4) and that the gendering of childhood is affected by various 'modernising' influences which tend towards universal understandings of child wellbeing, such as rights-based approaches that in turn often underplay gender differences among the young. 
The chapter draws on research from developing countries, and particularly on recent findings from Young Lives, a fifteen-year study of childhood poverty being carried out with 12,000 children in Ethiopia, India (in the State of Andhra Pradesh), Peru and Vietnam (see www.younglives.org.uk). Young Lives provides some of the most up-to-date data on children in developing countries, and, as a longitudinal study, can trace changes over time. Further, the countries were chosen to reflect a range of cultural, economic, geographic, political and social contexts and therefore echo several trends that occur more generally in the developing world. [1] They differ on international indicators of gender inequality, and according to the 2011 Human Development Report, Vietnam was ranked $48^{\text {th }}$, Peru 72nd and India 129th out of 176 countries on the Gender Inequality Index (UNDP 2011: 139-42) [2].

\section{How is gender in childhood framed in the literature?}

This section traces how gender within childhood has conventionally been framed in international development. Overall, it is accepted in policy circles that children and youth should be prioritised in development processes. Research from developmental and behavioural sciences conducted largely in industrialised countries has provided evidence concerning the factors influencing positive development in the young. This research conceptualises childhood as a lifephase shaped mostly by universal biological criteria. Recently having been taken up by development economics and applied to children in the developing world, this research emphasises the factors that affect human capital formation during childhood, and links children's competencies with adult outcomes. Highlighting the education and health 'investments' required to increase future economic performance, it proposes early childhood as the most critical window of opportunity for intervention (Heckman 2006). However, human capital approaches focus on individual characteristics, and tend to disregard power relations and socio-cultural factors in explaining differential outcomes for boys and girls.

Concern about the loss of developmental potential in childhood because of poverty and inequality and a desire to maximise human development potential has led to an emphasis in international development on measuring children's progress, with a focus on quantitative research in which gender is operationalized as a discrete variable. For the first time, a global coalescence to achieve the Millennium Development Goals (MDGs) (which set targets related to 
poverty, gender equality, and enrolment of children in primary school) has required systematic efforts to track changes in children's wellbeing over a 15-year period. But the limited availability of data that simultaneously disaggregates gender and age masks the gendered and generational dynamics of poverty (Jones et al 2008: 1), concealing power relations, as well as the responsibilities and perceptions of children, especially when data are collected at the household level. Scholars and activists are calling for the post-MDG development agenda to prioritise the identification and tackling of global inequalities, and the lens on gender in childhood is also increasingly focused on disadvantage, especially the problems faced by girls. This provides an opportunity to deepen understanding of how gender power operates in particular contexts, but will require better integration of quantitative and qualitative research approaches.

Attention to the 'improvement' of the human condition and the elimination of poverty often leads to a 'problematizing' approach to gender in childhood, where being a girl or boy is narrowly framed in relation to deficiencies or threats requiring intervention. The spotlight is commonly on children facing extreme risk and deprivation. The ordinary worlds of boys and girls are frequently overshadowed by categories of children requiring special protection - 'street children', 'orphans', 'child labourers' and 'trafficked children', for example. These categories are based on universal approaches to child protection with scant regard to how vulnerability is construed and experienced in local contexts (Myers and Bourdillon 2012). If gender is considered at all, the received wisdom is that girls are almost inevitably more disadvantaged and at greater risk than boys. Hence, a distinct narrative has emerged in the last 5 years, centring on the 'empowerment' of girls. Influential organizations including the UK Department for International Development (DFID), the World Bank and several UN agencies, have rallied behind 'girl-led development'. In 2008, the Nike Foundation, in collaboration with the NoVo Foundation, United Nations Foundation and the Coalition for Adolescent Girls, launched 'The Girl Effect', which is marketed as a 'revolution' to end global poverty, led by adolescent girls (see www.girleffect.org).

Much of this discourse is based on normative understandings of gender. International organisations advocate attitudinal, behavioural and policy change to bring about gender equality to safeguard girls' rights and to protect girls from harmful practices (Boyden et al. 2012). Girls' problems and sexualized risks permeate the priorities of child protection within developing countries, such that major international agencies have concentrated on protecting female minors 
from marriage, circumcision, sex-work, trafficking, and domestic work. Although 'girls' are the focus, there is no guarantee that the interventions aimed to improve their lives are informed by contextualized gender analysis. This raises questions about the evidence base of interventions, and the extent to which universal prescriptions to address child and youth poverty reflect young people's social worlds, including gendered experiences of poverty and livelihoods. Even if girls are prioritized, it is not possible to fully understand their situations without also paying attention to experiences, roles and perspectives of boys and young men, and constructions of masculinity.

At the same time, there are parallels between the way girls and women are cast within development discourses, as 'instrumental' to realizing the goals of economic growth, investments targeted at women and girls being described as 'smart economics' (World Bank) and 'intelligent design' (The Girl Effect). The rationale is economic, and the 'cost of excluding girls' is calculable: for example, in Uganda, 85 per cent of girls leave school early, seemingly resulting in $\$ 10$ billion in lost potential earnings. By delaying child marriage and early birth for one million girls, Bangladesh could potentially add $\$ 69$ billion to the national income over these girls' lifetimes.' [www.girleffect.org]. However compelling this narrative, development is not just about economics, and gender is not just about females (Jones and Chant 2009).

The dominance of normative assumptions about gender in childhood and the concentration on measuring the effects of gender inequality raises concerns about the neglect of the phenomenological dimensions of gender, and the way gender mediates boys' and girls' evolving identities and experiences. Since the 1980s, a growing number of studies in developing countries have focused on the diverse social and cultural constructions of childhood, and on children's perceptions, roles and responsibilities, the constraints on their agency and everyday experience. Bringing together perspectives from anthropology, sociology and human geography, the views and interpretations of young people are sources of data, and the methods are qualitative. This research demonstrates that constructions of gender in childhood vary across time and space. Young people are active in creating their gender identities, and even where gender 'gaps' may not be significant, gender mediates young people's experiences, including their experiences of poverty.

\section{Gender differences among children and young people}


Here we trace some trends in gender in developing countries, from birth to early adulthood, describing patterns of survival, school attendance, children's work activities, lifecourse changes, and risks and reputation.

\section{Birth and survival}

The number of males per 100 females, or human sex ratio, differs greatly between countries and regions. In many countries, female disadvantage in survival during childhood has declined dramatically in recent decades, and life expectancy at birth has increased for both boys and girls. However, India and China have an abnormally high human sex ratio of 106, and in India the ratio has increased over the last century (Bhattacharya 2013). A combination of factors explain this - female infanticide was (and to an extent continues to be) practiced, girls received less medical care than boys, and female children tended to be neglected. In India, ultrasound foetal scanning has led to a rapid increase in female foeticide, which is more prevalent in urban areas and among well-educated women, though this does vary across the country, and is more common in the north-western states. The preference for sons in India and China tends to be explained by patrilineal kinship systems where married daughters become part of their husbands' families (Bhattacharya 2013). In India, this is exacerbated by the continuing and spreading practice of dowry payments; legislation has been ineffective in eradicating the practice and sex determination tests and female foeticide have been marketed with slogans such as 'Spend Rs. 500 now, save Rs. 50,000 later' (Bhattacharya 2013 p127).

Proverbs are indicative of cultural values favouring boys, such as in Andhra Pradesh where there is a saying, 'It is better to be born as a tree in a jungle than to be born a girl,' and another, 'Bringing up a daughter is like watering a plant in another's courtyard.' In Vietnam, where the number of male births compared to female births has risen, sons are essential to their parents because they carry on family lineage and names and perform ancestor worship; they are expected to take care of parents in old age; and having a son improves women's status in the family and confirms men's status in the community.

\section{School attendance}

The huge effort expended on meeting the MDGs means that enrolment in primary school is now the norm globally and the emphasis on gender equity has resulted in girls' enrolment 
increasing at a faster rate than that of boys, narrowing the gender gap at primary level. The United Nations (2012) reports that overall gender parity in primary schooling has been achieved worldwide, although gender inequalities persist in some regions and countries. Sub-Saharan Africa has the highest rate of girls out of primary school, at 26 per cent; girls also account for 70 per cent of the total share of primary-age out-of-school children in Northern Africa. In Southern and Western Asia, the percentages are 55 and 65 respectively. In Northern Africa, between the 1990s and 2000s, the attendance gap between poor girls and boys was reduced by more than half. Despite progress in closing gender gaps at primary level, large differences in attendance persist between rich and poor in all regions. Moreover, there has been little progress since the 1990s in closing secondary attendance gender gaps (ibid).

Within Young Lives, analysis of pre-school access for children aged between 3 and 5 years found small differences between boys and girls (compared with socio-economic differences), which were often not statistically significant (the largest being a 5 percentage point difference favouring boys in rural Peru, much smaller than other socio-economic related gaps) (Woodhead et al 2013). Nevertheless, gender differences are more evident during middle childhood, as children become progressively integrated into the household economy, undertaking domestic tasks which are differentiated along gender lines that reflect adult patterns. Typically, children balance schooling with a range of economic activities. Boys usually spend more time doing paid or unpaid work on family farms, while girls spend more time caring for others and on domestic tasks. That said, sibling composition and birth order have been shown to be as important, or more important, as gender in shaping roles and time use in some countries (cf Punch 2001).

While gender parity in primary school enrolment was achieved in all four Young Lives countries by 2009 , children's trajectories beyond primary school reveal different patterns. At age 15 , in Vietnam, boys were less likely (72\% compared to $80 \%$ girls) to be in school in 2009 and the disparity is intensified by poverty, as only $40 \%$ of poor boys were in school at age 15 , compared to $52 \%$ of poor girls. In Andhra Pradesh, more girls than boys had left school at this age, yet poor girls were more likely to be in school than poor boys. This may be the result of policies that aim to keep girls in school. However, the quality of schooling that children receive varies, and overall, using the results of vocabulary and maths tests as a proxy for quality, Young Lives has found that boys perform better in Andhra Pradesh and Ethiopia, while girls perform 
better in Vietnam. In Ethiopia and Andhra Pradesh, girls may miss school for several days each month during menstruation, due to the lack of sanitation at school, and in Andhra Pradesh, girls report distance to school and inadequate transport as reasons for discontinuing. A rapid growth in low-fee private schools in Andhra Pradesh has further favoured boys as parents generally spend more on their sons' education and by $2009,39 \%$ of boys and $23 \%$ of girls aged 8 were in a private school. Though unregulated, private schools tend to perform better than government schools.

Overall, gender differences are more pronounced in Andhra Pradesh and to a lesser extent Ethiopia than they are in Vietnam and Peru (Woodhead et al 2013). Gender disparities in childhood are often interpreted as evidence of entrenched discrimination. However, decisions affecting girls and boys are regularly made in light of restricted options and resources, and frequently reflect calculations of the short and longer-term risks and advantages of various alternatives, bearing in mind boys' and girls' employment, marriage and social mobility prospects. For example, in Andhra Pradesh the opportunity costs of schooling are higher for girls than for boys, because girls are less likely to obtain well-paid jobs or to contribute to the natal home when they marry, which may be at a relatively young age. As a result, parents tend to discourage their daughters from remaining at school beyond the acquisition of basic skills. In contrast, investments in boys' education are made with the expectation of future returns, so boys are more likely to be encouraged to remain at school and/or enter private schools. As one mother explained: 'We wanted to stop [our daughter] from further studies.... Will she give us money once she starts working? Who will she give it to? We won't make anything from her. She is better off working here...'. Such gendered practices appear to be transmitted through the generations in some communities, producing a systematic bias against girls. Lower educational aspirations of parents for their daughters at age 12 may be linked to girls having lower educational aspirations for themselves, as well as lower scores in both math and verbal tests by age 15 (Dercon and Singh 2013).

Though gender disparities can be discerned, other factors associated with household wealth and levels of education of caregivers, rural or urban location, ethnicity, language or caste, explain greater gaps between children's outcomes (Dercon and Singh 2013). This is apparent even in Andhra Pradesh, where gender difference is most pronounced. The difference between access to private schooling for boys and girls is smaller than that between children in rural and 
urban areas, or between children with more and less educated mothers, or between children from traditionally deprived caste and tribal groups and the other castes (Dercon and Singh 2013). Often, the effect of gender disparities is most evident when they co-occur with and exacerbate other processes of socio-economic, cultural and/or spatial differentiation.

\section{Children's work and time use}

Gender norms influence children's roles and responsibilities, how they are treated, their experiences, and their aspirations, especially as they enter middle and late childhood. But within the context of children's lived experience, it is impossible to separate gender out from other dimensions of their evolving identities and from the multiple hierarchies that they navigate. In her ethnographic study in rural Bolivia, Punch (2001) finds that children's roles and time-use were not determined solely by gender, and that household composition and sibling birth order also explain the assignment of work tasks. Gender is one among several considerations in this respect. Thus, gender cannot be reduced to something that individual boys and girls 'have'; rather, gender is based in complex social processes of which children are a part. So, in addition to being gendered, childhood is also generationed, classed, raced, sexualized, embodied, spatialized (Alanen 2009). Heissler and Porter (2012) find that in Ethiopia the nature and amount of work done by children is affected less by levels of household poverty than by economic shocks, such as illness and death in the family. But they also establish that girls and boys are affected differently by household circumstances, with girls working more overall and on domestic tasks when their mothers are ill or absent. Boys appear to work less in larger households, while girls work more if they have sisters, and if they have younger brothers. Both boys and girls seem to be affected by adverse events generally, but boys work more when the household has more livestock. A shortage of children may lead to the blurring of gender roles. Though this ensures that all the tasks necessary for household maintenance are accomplished, it can be a source of considerable discomfort for the boys and girls concerned (Heissler and Porter 2012).

\section{Youth-risk and reputation}

Gender differences become more pronounced during life-course transitions such as puberty, leaving school, commencing work, or marriage, and at times of crisis. Research 
demonstrates the uneven impact of modernization on young people's transitions, and there is a growing discourse on the failures of development as evidenced by the problem of youth unemployment and unfulfilled aspirations. Studies examining the challenges in the transition to social adulthood tend to focus on the experiences of young men. Jeffrey (2010) shows that many young men in Uttar Pradesh, India, acquire copious qualifications, but, in a competitive labour market where opportunities are structured by caste and other political considerations, are unable to find jobs that require their skills, and remain in a limbo of student-hood. Young men in a diversity of contexts globally articulate their frustrations in terms of 'waiting', 'boredom', 'timepass', and being 'stuck'.

Jones and Chant (2009) explore the 'crisis of youth' in The Gambia and Ghana, and question whether the confidence placed in education and employment is justified. They emphasise that despite efforts to increase girls' school enrolment and employment, social norms continue to dictate that the bulk of reproductive work is done by young women, thereby constraining the amount of time they can dedicate to schooling, and to making contacts that are relevant to securing paid work. Similarly, a study of male Palestinian youth living in a refugee camp in Jordan finds that those young men who successfully displayed the dominant form of masculinity in the camp (maukhayyamji) risked marginalization from wider Jordanian society, including through access to jobs and resources (Hart 2008). The transition from childhood to adulthood is therefore not a straightforward process, and young people in the developing world struggle to meet the gendered social expectations placed on them within the context of limited opportunity.

Young Lives research also finds that young people actively pursue education in the hope that it will enable them to secure respectable jobs (Camfield 2011, Crivello 2011, Morrow 2013). However, many are disappointed by the outcome and resist taking on menial labour for risk of social shame; this phenomenon seems to affect both girls and boys. Gendered social expectations also constrain boys and girls alike. Young men and women share many concerns - for example, contributing to household welfare, securing a good marriage, earning a 'good name', and these concerns are shaped by gender norms. Social risks also influence perceived options, especially when neighbourhood environments are deemed to be dangerous. For example, families living in a shanty town on the outskirts of Lima worry about the presence of gangs and drug dealers and 
the prevalence of violence. Parents are especially resistant to letting their daughters work outside at this age, although some girls earn money by working from home, sewing or making jewellery. Susan is sympathetic to her mother's insistence that she not leave the house alone: 'Because I think there's a lot of danger on the streets... the thing nowadays is robbing... they can steal something from you.' Girls see themselves as and are construed as, potential victims of violence. A parallel desire is to protect boys from being drawn into 'bad company'. One mother said, 'it's about what he might get himself involved in, because here... it's where the gang members smoke [drugs]...so there are times you can't even let the kids leave [the house]. And if they do, you have to be watching them.'

Gender-differentiated social risks are also a concern for young people in Addis Ababa. Young women articulate everyday fears of rape and harassment, and general physical insecurity. Such fears are instrumental in constraining their mobility, and girls seek work close to home, for example, assisting mothers in laundering, or food preparation for sale, whereas boys find jobs in the local market. In short, not only are young people's livelihood opportunities differentiated by gender, but differing moral judgements are made about boys' and girls' choices, respectively, even when these choices are constrained by poverty. These examples underscore the moral values that shape how boys and girls negotiate their everyday socio-spatial environments.

In Andhra Pradesh and Ethiopia, making a 'good' marriage for daughters is a priority, with chastity a criterion of eligibility. In some communities, the social standing of households depends on the conduct of unmarried female members, and any breach is a social risk for the individuals involved and for their families. Particularly in Muslim communities in Andhra Pradesh, the need to limit the interaction between unmarried girls and unrelated males inhibits girls' movement outside the home, especially after puberty. This often results in the weakening of their social networks, as they spend less time with school friends - male and female - and more time with siblings and relatives within the home (see Boyden and Crivello 2012). Earning a good name for oneself is also important for boys, and by age sixteen, boys are often concerned about how to maximise their chances of a good marriage. For example, Salman described how formal qualifications would improve his marriage prospects. When initially interviewed, he was not interested in marrying an educated girl, but his views changed over time. He worried that eligible girls will prefer to marry an educated boy, not 'this boy who drives an auto, or 
rickshaw'. This reflects how he sees himself. Boys' greater access to mobility may be a resource for material and social gain, but it is not a guarantee, and girls may be excluded from such opportunities due to rigid gender norms.

With the growing focus on schooling for children, children's migration for education is a key strategy for accessing better facilities, and gender norms influence decisions regarding child migration. In rural Peru, young people and their families look to the city as a place of opportunity, and migration is increasingly considered an inevitable element in the pursuit of wellbeing. A mother in Peru explains, 'more and more, we're more alone, it's not like it was before where you're with your children. This is the change with children, they begin to leave, and one feels... more alone.' Where girls' moral reputations are strongly guarded, family networks are often crucial to their migration and to overcome restrictions on their mobility. For

older children and youth, mobility is also a resource for accessing post-secondary education, and for pursuing livelihoods. Their options are structured by gender processes, such as the gendered nature of personal networks, household responsibilities and labour markets. For example, constraints on youth mobility in Lusaka, Zambia are described as 'getting stuck in the compound' and accessing other parts of the city depend on young people's households, skills and resources and their use of the city (Hansen 2005). Young women lack job contacts and economic means relative to young men, and cannot afford public transportation. Mobility and material inequalities are thus deeply gendered processes.

\section{The gendered impacts of modernity: continuity and change?}

Despite the persistence of long-standing gender norms and hierarchies, the experience of childhood in developing countries is changing rapidly due to the restructuring of economies, advances in technology, infrastructure and communications and the spread of basic services. Internal and international migration are on the rise, and the experience of childhood is increasingly urban; it is estimated that by 2050,7 in 10 people will live in cities and towns. New information and communication technologies (ICT), including low-cost internet, present new opportunities for the young and are tools that can help improve their living conditions and expand their horizons. But access remains uneven across the Global North and South, between rural and urban locations, and between male and female users. Studies suggest that technological 
innovation does not automatically alter fundamental gender and age-based asymmetries in society. Modernising influences may represent welcomed social change, but increasingly accessible communication tools like mobile phones and internet can also represent risks to established gender relations; modernity does not therefore guarantee greater freedoms for girls.

At the same time, schooling has fast become one of the defining features of modern childhood, and increasingly shapes children's lives, changing their use of physical space and time, their relationships with and responsibilities towards others, and their aspirations. Earlier, the transition to adulthood was achieved through the assumption of increased gendered responsibilities and by means of marriage and parenthood. Today, schooling plays an increasingly decisive role in shaping social transitions and children's futures. Importantly, public education systems are invariably structured along lines of age and grade and most attempt to minimise gender distinctions, for example through coeducational provision at primary, and sometimes secondary, level, as well as shared school curricula. Though biases still exist in education, shown above, mass schooling may gradually give rise to a less gendered conception and experience of childhood that applies across economic and socio-cultural groups as well as geographic localities. However, ensuring gender neutrality in schooling is far from straightforward and may in practice inhibit girls' attendance, for example when shared toilets infringe notions of gender propriety.

Among the Young Lives countries, overall, gendered experiences and expectations of childhood seem to have shifted most noticeably in Ethiopia (Boyden et al 2012). As part of a wider commitment to socio-economic development, the Government has been keen to change attitudes and practices towards children, with the intention of achieving greater gender parity and eliminating customs that are deemed to be harmful to girls in particular. Government intervention has ranged from comprehensive services, such as the development of education and health systems, to measures intended to modify gendered practices, such as female circumcision and (female) marriage below age eighteen. These measures have had a dramatic impact on gendered expectations even within one generation. Thus, while the majority, of mothers and grandmothers in Ethiopia have been circumcised, had limited or no schooling and were already in arranged marriages by the time they reached puberty, many of their daughters and granddaughters are not circumcised, are remaining at school to secondary level, staying 
unmarried until their late teens or early twenties, and aspiring to professional careers.

Nowadays, most girls express a desire to delay marriage and to bear less children than women of their mothers' and grandmothers' generation, or at least to marry later than their mothers. Yet gendered social transitions in childhood and youth remain important and are marked by rites of passage, for example in Andhra Pradesh at menarche, when girls and their families celebrate becoming a 'big girl'. In Peru, many girls celebrate their fifteenth birthdays with a quineañera ceremony. In Ethiopia, boys celebrate getting their first goat or small plot of land.

Moreover, in all four Young Lives countries there are weaknesses in school systems, ranging from limited availability and accessibility, especially in rural areas, to poor school quality and high costs of attending. Uncertainties about the value and relevance of schooling lead to contingency planning by boys and girls; depending on perceptions of the relative benefits of school and work at a particular moment, they may move in and out of school. Families may also strategize to maximise benefits to the household, so that an elder or younger child, a girl or a boy, or maybe a child that is brighter academically than her/his siblings, is singled out to remain at school while others work.

Behavioural and attitudinal change in respect of gender is not a linear process, but reflects a complex mix of shifting and sometimes competing, or even contradictory, understandings. Generational differences in views about gender may lead to conflict within families. New ideas give rise to new concerns about children's wellbeing, some of which are gender-specific. For example, attending school can compromise traditional conceptions of appropriate behaviour in girls, especially following puberty when their social identity becomes more sexualised (Boyden and Crivello 2012). In Ethiopia, where marriage is critical to girls' successful transition to adulthood and is customarily arranged by the couple's parents, delayed marriage may be seen as a social threat to young females, heightening the possibility of promiscuity, sexually transmitted infections, abduction, single parenthood and abandonment by partners. Similarly, while the majority of parents appear to view completing education as the best way for girls to secure their futures, others regard extended schooling as a potential risk, because girls are less likely to marry while at school. In other words, though education is considered an investment, it is but one of many social expectations that young people must negotiate, and 
different generations may have different views about what matters most for individual children and/or their families.

\section{Conclusions}

Gender differences in childhood are often overshadowed by the research and policy focus on human capital. Gender is a vital element in how boys and girls experience the world and their identities. Gender mediates and structures everyday life, influencing how children and young people are incorporated within their households and communities. This point is often eclipsed by a tendency to study 'outcomes' in poor children, disconnected from everyday experience. Thus, gender differences grow during middle and later childhood, shaped by changing expectations of girls and boys, which are in turn framed by the socio-economic circumstances of the household as well as by perceived social risks and opportunities. Gender also underpins young people's evolving moral identities. However, gender is but one form of social power and intertwines with other social factors, and as we have seen, poverty intersects with gender and remains a powerful constraint on boys' and girls' trajectories.

In conclusion, gender is dynamic and gender disparities in childhood sometimes confound common assumptions. Gender shapes children's lives in crucial, though complex, ways. A balanced picture is needed, which recognises the ways some inequalities develop progressively through childhood, while others can open up through specific life events, and yet others are amplified as children face key transitions. Gender inequalities offer a clear example of these processes. Global and local processes of economic, social, cultural, environmental change are creating new opportunities and constraints. Finally, policies aimed at reducing gender-based difference need to engage with the context that influences parents' and children's choices, as well as discrimination (and the way different forms of gender discrimination interconnect with other forms of discrimination based, for example, on age, race/ethnicity and class). Policies need to take account of how programmes may impact differently on boys and girls, and the gendered nature of poverty across the life course.

\section{Endnotes}

[1] Peru, Vietnam and India have experienced consistent economic growth since the study began, but high levels of social and economic inequality persist. Ethiopia remains a low-income 
country, despite averaging $11 \%$ growth for six years up to 2009 . While gender norms appear relatively stable in some areas in these countries, gendered experience is affected by everchanging forces that affect individuals and groups at various societal levels. Household factors such as wealth and security of livelihood are often decisive, as are macro-level mechanisms, such as media representations, institutional structures and political-economic processes (Woodhead et al 2013).

[2] Data were not available for Ethiopia. The Gender Inequality Index reflects women's disadvantage in reproductive health, empowerment and the labour market.

\section{References}

Alanen. L. 2009. The Generational Order, In The Palgrave Handbook of Childhood Studies (eds. Qvortrup, J, Corsaro, W, and Honig, S) Basingstoke: Palgrave Macmillan.

Bhattacharya, P. 2013. Gender inequality and the sex ratio in three emerging economies. Progress in Development Studies, 13, 2, pp117-133.

Boyden, J. \& Crivello, G. 2012. Political Economy, Perception and Social Change as Mediators of Childhood Risk in Andhra Pradesh. In Boyden, J. \& Bourdillon, M. (eds), Childhood Poverty Multidisciplinary Approaches. Basingstoke: Palgrave Macmillan

Boyden, J., Pankhurst, A., \& Tafere Y. (2012) Child Protection and Harmful Traditional Practices: Female Early Marriage and Genital Modification in Ethiopia. Development in Practice, 22(4), 510-522.

Camfield, L. 2011. 'From School to Adulthood'? Young People's Pathways through Schooling in Urban Ethiopia. European Journal of Development Research, 23(5), 679-694

Crivello, G .2011. Becoming somebody: Youth transitions through education and migration in Peru. Journal of Youth Studies, 14(4): 396-411.

Dercon S, and Singh, A. 2013. From Nutrition to Aspirations and Self-Efficacy: Gender Bias over Time among Children in Four Countries. World Development, (45): 31-50.

Hansen, K. 2005. Getting Stuck in the Compound: Some Odds against Social Adulthood in Lusaka, Zambia, Africa Today, 51(4): 3-16.

Heckman, J., Stixrud, J., and Urzua, S. 2006. The Effects of Cognitive and Noncognitive Abilities on Labor Market Outcomes and Social Behavior, Journal of Labor Economics, 24(3): 411-82. 
Hart, J. 2008. Dislocated Masculinity: Adolescence and the Palestinian Nation-in-exile, Journal of Refugee Studies, 21(1): 64-81.

Heissler, K and Porter, C. 2012. Know Your Place: Ethiopian Children's Contributions to the Household Economy. Young Lives Working Paper number 61.

Jeffrey, C. 2010. Timepass: waiting, micropolitics and the Indian middle class. Stanford, CA: Stanford University Press.

Jones, G. and Chant, S. 2009. 'Globalising initiatives for gender equality and poverty reduction: Exploring 'failure' with reference to education and work among urban youth in the Gambia and Ghana. Geoforum, 40:184-196.

Jones, N, Holmes, R, and Epsey, J (2008) 'Gender and the MDGs', ODI Briefing Paper, http://www.odi.org.uk/sites/odi.org.uk/files/odi-assets/publications-opinion-files/3270.pdf

Morrow, V. 2013. Troubling transitions? Troubling transitions? Young people's experiences of growing up in poverty in rural Andhra Pradesh, India. Journal of Youth Studies 16, 1, 86-100.

Myers, W and Bourdillon, M (2012) Introduction: Development, children and protection, Development in Practice, 22(4): 437-447.

Punch, S. 2001. Household division of labour: Generation, gender, age, birth order and sibling composition. Work, Employment \& Society 15(4), pp. 803-823.

United Nations (2012) The Millennium Development Goals Report: Gender Chart, http://www.unwomen.org/wp-content/uploads/2012/12/MDG-Gender-web.pdf

UNDP (2011) Human Development Report 2011. Sustainability and Equity: A Better Future for All, New York: United Nations Development Programme

Woodhead, M., Murray, H., and Dornan, P. (2013). What inequality means for children. Evidence from Young Lives. Oxford: Young Lives. 